NOTA TÉCNICA

\title{
RELACIÓN ENTRE LA PRECIPITACIÓN PLUVIAL Y EL CRECIMIENTO SECUNDARIO EN AMARANTO (Amaranthus hipochondriacus L.) ${ }^{1}$
}

\author{
José S. Barrales ${ }^{2}$
}

\begin{abstract}
RESUMEN
Relación entre la precipitación pluvial y el crecimiento secundario en amaranto (Amaranthus hipochondriacus L.) El crecimiento secundario de 10 genotipos de amaranto cultivados en dos localidades de Valles Altos de México (Chapingo, Mexico y Cuapiaxtla, Tla.) se relación con la cantidad de lluvia ocurrida durante el periodo de crecimiento reproductivo. En Chapingo, hubo una mayor presencia de crecimiento secundario conforme la cantidad de lluvia fue mayor en periodo de crecimiento reproductivo. Hubo $82,8 \%$ de plantas con crecimiento secundario cuando la lluvia fue de $289,7 \mathrm{~mm}$, de $74,2 \%$ con una lluvia de $225,2 \mathrm{~mm}$ y de $4,2 \%$ con lluvia de $162,1 \mathrm{~mm}$. En Cuapiaxtla, Tla. no se presentó crecimiento secundario, la lluvia promedio en periodo de crecimiento reproductivo de los genotipos evaluados, fue de $118,2 \mathrm{~mm}$.
\end{abstract}

\begin{abstract}
Relationship betwen amount of rain and secondary growth in amaranth (Amaranthus hipochondriacus L.). In Chapingo, Mex. (L1) and Cuapiaxtla, Tlax. (L2) in México, secondary growth in amaranth was evaluated in relation to the amount of rain during the reproductive growth period (GRP). 10 types of amaranth were evaluated in three sowing dates in L1 and 2 sowing dais in L2 in 1994. In general for all types of amaranth, when the rain was $289.7 \mathrm{~mm}$ during GRP, $82.8 \%$ of plants showed secondary growth; with rain of 225.2 $\mathrm{mm}$ during GRP, $74.2 \%$ of plants presented secondary growth; meanwhile with $162.1 \mathrm{~mm}$ of rain during GRP, secondary growth affected only $4.2 \%$ of plants. Finally, in L2 the rain in GRP was $118.2 \mathrm{~mm}$ without the presence of secondary growth.
\end{abstract}

\section{INTRODUCCIÓN}

A pesar de que varios autores se refieren al amaranto (Amaranthus hipochondriacus L.), como una especie sin problemas fitosanitarios o fisiológicos durante su cultivo, existen algunos factores que influyen negativamente en su potencial de rendimiento, tales como el crecimiento secundario, mencionado como tal por Grubben y Van Sloten (1981). El crecimiento secundario (CS) en amaranto es la formación de pequeñas hojas de color verde en las inflorescencias, en lugar de la formación de grano causando una disminución en el rendimiento. Dada la importancia que puede tener este fenómeno para la producción de amaranto, se planteá como objetivo del presente trabajo determinar si existe una relación entre la precipitación pluvial ocurrida en el periodo de crecimiento reproductivo (PCR, definido desde la emergencia de la panícula hasta la madurez fi- siológica (Barrales, 1988) y la presencia de crecimiento secundario en un grupo de amarantos provenientes de plantas que presentaron este problema, en ensayos de rendimiento hechos en 1993.

Respecto a la lluvia, se indica que el amaranto en México se cultiva en regiones con precipitación pluvial anual entre 400 y $1300 \mathrm{~mm}$ anuales (Reina, 1990), aunque es posible encontrarlo incluso en áreas con lluvia anual fuera de este rango. En 1993 en Chapingo, México en varios ensayos de rendimiento se manifestó mucho crecimiento secundario, con una precipitación pluvial de $560,6 \mathrm{~mm}$ durante el ciclo biológico, registrándose en promedio alrededor del $60 \%$ de ésta durante el periodo de crecimiento reproductivo (Barrales, 1993), por lo que se plantea la hipótesis sobre la existencia de una relación de este elemento climáico con la deformación morfológica causada por el crecimiento secundario.

Presentado en la XLII Reunión Anual del PCCMCA, en El Salvador, Centroamérica, 1996.

2 Universidad Autónoma Chapingo. Chapingo, MJx. 056230. 


\section{MATERIALES Y MÉTODOS}

En las localidades de Chapingo, Mex. (Ll; 19/29'N, 98/53'W y $2250 \mathrm{msnm}$ ) y Cuapiaxtla, Tlax. (L2; $19 / 18^{\prime} \mathrm{N}, 98 / 15^{\prime}$ 'W y $2450 \mathrm{msnm}$ )(García, 1981) se evaluaron diez genotipos de amaranto de dos colores (siete rojas y tres verdes) provenientes de plantas con crecimiento secundario durante 1993. Se establecieron tres fechas de siembra en L1 (FS1 = 13-04-94, FS2=12-0594 y FS3=20-05-94), y dos en L2 (FS1 =21-05-94: FS2=02-06-94) en un diseño de bloques al azar con dos repeticiones. Las matas se colocaron a $40 \mathrm{~cm}$ de distancia, en parcelas de dos surcos de $85 \mathrm{~cm}$ de ancho y seis metros de largo. En cada lote experimental se registró la lluvia acumulada en cada semana, para después acumularUrcantidad de lluvia desde la emergencia de plantas a la fase de emergencia de la panícula, durante el período de crecimiento reproductivo (PCR) y durante todo el ciclo biológico (KB).

Se contaron las plantas con crecimiento secundario (PCS) dentro de cada genotipo, se expresó en porcentaje, en relación con la población total de plantas. Se evaluó el rendimiento expresado en gramos de semilla por planta. El análisis de varianza se efectuó por localidad, pero sólo incluyeron los resultados para Chapingo, Méx. por ser en esta localidad donde hubo crecimiento secundario.

\section{RESULTADOS Y DISCUSIÓN}

Sólo para la variable días a emergencia de panícula hubo diferencias estadísticas para la interacción tratamientos por fecha de siembra.

En Cuapiaxtla, Tlax. no ocurrió crecimiento secundario, debido posiblemente a la reducida cantidad de lluvia durante el período de crecimiento reproductivo de los genotipos evaluados.

En Chapingo en las tres fechas de siembra, la emergencia de plántulas ocurrió a los 10 días después de la siembra (DDS). Se esperaba un patrón definido del crecimiento secundario (CS) a través de las fechas de siembra producto del cambio de ambiente a lo largo del año, mismo que no ocurrió. Se encontró que la manifestación de CS fue mayor en la FS1, seguida de la FS3 y finalmente en la FS2 (Cuadro 1). En esta variable se detectaron diferencias significativas sólo a nivel de fechas, resultando no significativa para la interacción fechas por genotipos.

La lluvia durante el PCR, fue de $289.7 \mathrm{~mm}$ en la FS 1, de 162,1 en FS2 y de 225,2 mm en FS3. Se observó cierta relación con la magnitud de CS, que fue de $82,8 \%, 4,2 \%$ y $74,2 \%$ respectivamente con las FS. La cantidad de lluvia fue un factor importante, pero quizás lo más influyen el CS, fue la nubosidad, alta humedad relativa y la disminución en la temperatura, condiciones ambientales que predominan durante los tiempos de lluvia. Además, debe considerarse lahumedad edáfica, que es un factor para promover el crecimiento.

El amaranto se reconoce como de fotoperiodo corto (Duncan, 1980), aspecto que se confirma en los amarantos precoces en los cuales se observó un retraso en la emergencia de panícula conforme se retrazó la fecha de siembra (Cuadro 1), donde el fotoperiodo se hace más largo. En la época de lluvias la nubosidad redujo la intensidad de radiación solar, sometiendo al amaranto a condiciones desfavorables para su desarrollo por ser una planta $\mathrm{C} 4$, lo que seguramente causa que se manifieste el caracter de hábito de crecimiento indeterminado promoviendo el crecimiento de pequeñas hojas en lugar de la formación del grano.

Durante el ciclo biológico de los amaranto s evaluados la cantidad de lluvia fue en promedio de 511,2 $\mathrm{mm}, 435,4 \mathrm{~mm}$ y $550 \mathrm{~mm}$ para las FS1, FS2 y FS3 respectivamente, valores poco contrastantes, sin embargo las cantidades que se registraron sólo en el PCR si fueron contrastentes (Cuadro 1). Por otro lado, la magnitud de lluvia en el periodo de crecimiento vegetativo influyó en altura de planta, ya que en la FS1 las plantas tuvieron de 2,8 a 3,0 m de altura, en la FS2 de 2,0 a 2,2 $\mathrm{m}$ y en la FS3 de 2 a 2,3 m. En otro trabajo se encontró que la lluvia acumulada desde la emergencia de plantas hasta la emergencia de panícula tuvo una correlación negativa con la altura de planta $(\mathrm{r}=-0,58 * *)$ (Barrales $e t$ al., 1992), aspecto que se ratifica en este trabajo.

La presencia de plantas con crecimiento secundario (PCS) por fechas de siembra, no tuvo un marcado efecto sobre el rendimiento por planta. En esta variable se encontró una tendencia descendente de la primera a tercera fecha de siembra (Cuadro 1), el rendimiento en la FS 1 , fue $24,1 \%$ mayor que en la FS2 y $94.4 \%$ mayor que la FS3; también la FS2 fue mayor que FS3 en $56.6 \%$. Lo anterior puede evidenciar la capacidad de producción que tiene el amaranto, y corroborar en parte lo que los productores manifiestan, respecto a que el crecimiento secundario (CS) no afecta al rendimiento; sin embargo, a nivel de genotipos hubo cambios en longitud de panoja. Se detectaron diferencias estadísticas entre genotipos por longitud de panoja (Figura 1). También hubo diferencias en rendimiento por planta (Figura 2) y su sensibilidad al crecimiento secundario.

Para reducir el CS es importante detectar genotipos que no muestren interacción con la lluvia en el PCR, mismos que pueden buscarse evaluando los recursos genéticos que existen en México (Espitia, 1991), o bien 
Cuadro 1. Lluvia en varios períodos vegetativos de amaranto, sembrado en tres fechas de siembra, relacionado con presencia de crecimiento secundario. Chapingo, México. 1994.

\begin{tabular}{|c|c|c|c|}
\hline \multirow[b]{2}{*}{ Variables } & \multicolumn{2}{|c|}{ Fecha de siembra } & \multirow[b]{2}{*}{$30-05-94$} \\
\hline & 23-04-94 & $20-05-94$ & \\
\hline Crecimiento secundario (\%) & $82,8 " 12,2$ & $4.2 " 4,9$ & $74,2 " 12,1$ \\
\hline \multicolumn{4}{|c|}{$\begin{array}{l}\text { Número de días y lluvia a la emergencia de panícula (mm) } \\
\text { genotipos precoces }\end{array}$} \\
\hline días & 47 & 60 & 65 \\
\hline $\begin{array}{l}\text { lluvia } \\
\text { genotipos tardios }\end{array}$ & 75,8 & 171,0 & 289,5 \\
\hline días & 85 & 85 & 85 \\
\hline lluvia & 221,5 & 273,3 & 324,8 \\
\hline $\begin{array}{l}\text { Lluvia en el periodo de crecir } \\
\text { promedio }\end{array}$ & 289,7 & 162,1 & 225,2 \\
\hline $\begin{array}{l}\text { lluvia durante el ciclo biológi } \\
\text { promedio de } 150 \text { días }\end{array}$ & 511,2 & 435,4 & 550,0 \\
\hline $\begin{array}{l}\text { Plantas con crecimiento secu } \\
\text { total } \\
\text { por color }(\%)\end{array}$ & 154,0 & 10,0 & 271,0 \\
\hline rojo intenso & 20,7 & 60,0 & 34,7 \\
\hline verdes & 35,1 & 20,0 & 12,5 \\
\hline rojo claro & 44,2 & 20,0 & 52,8 \\
\hline $\begin{array}{l}\text { Altura final de planta }(m) \\
\text { rango }\end{array}$ & $2,8-3,2$ & $2,0-2,2$ & $2.0-2,3$ \\
\hline Peso de grano por planta $(\mathrm{g})$ & 49,4 & $3, .8$ & 25,4 \\
\hline
\end{tabular}

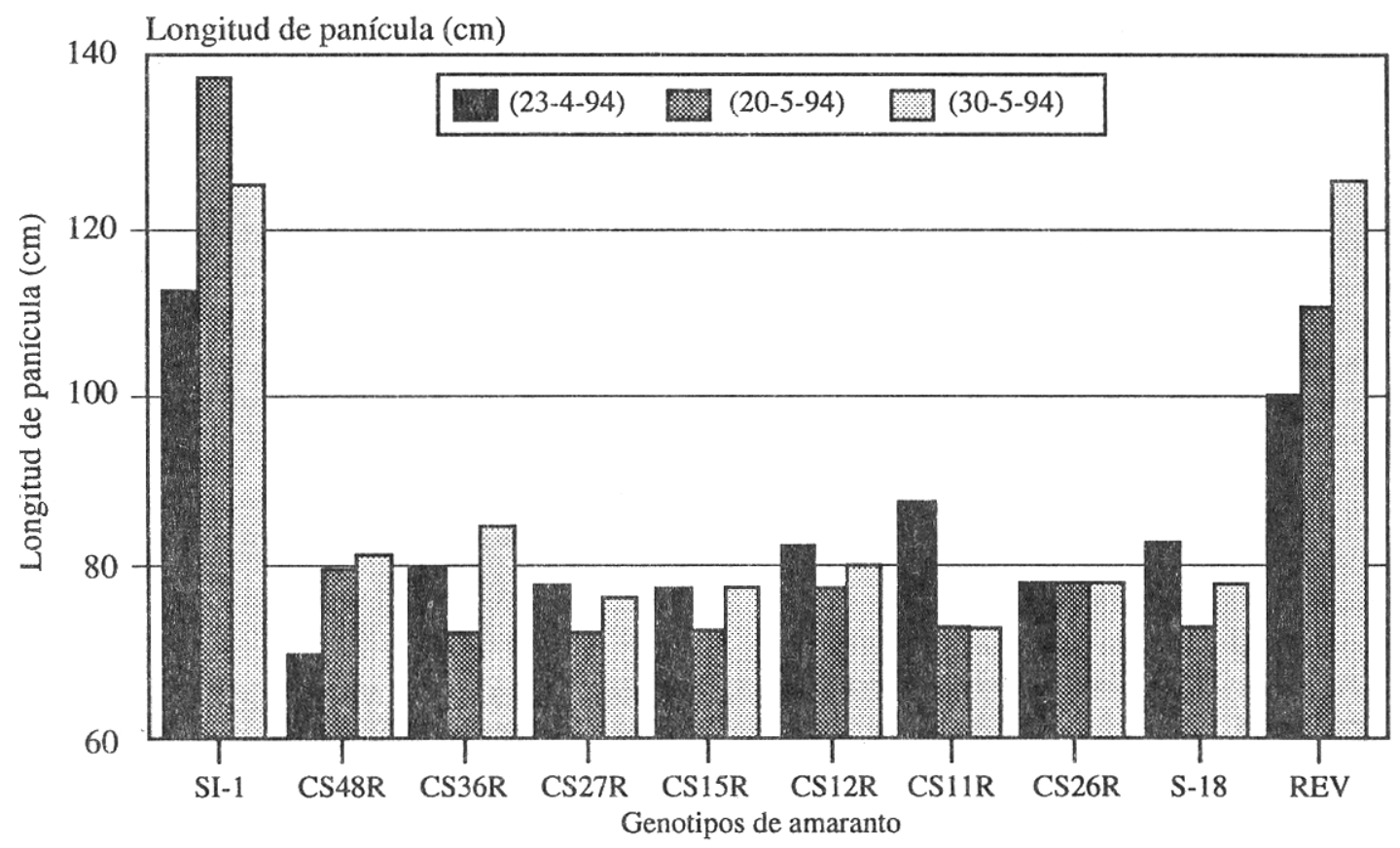

Fig. 1. Longitud de panícula en 10 materiales genéticos de amaranto, evaluados en tres fechas de siembra. Chapingo, México. 


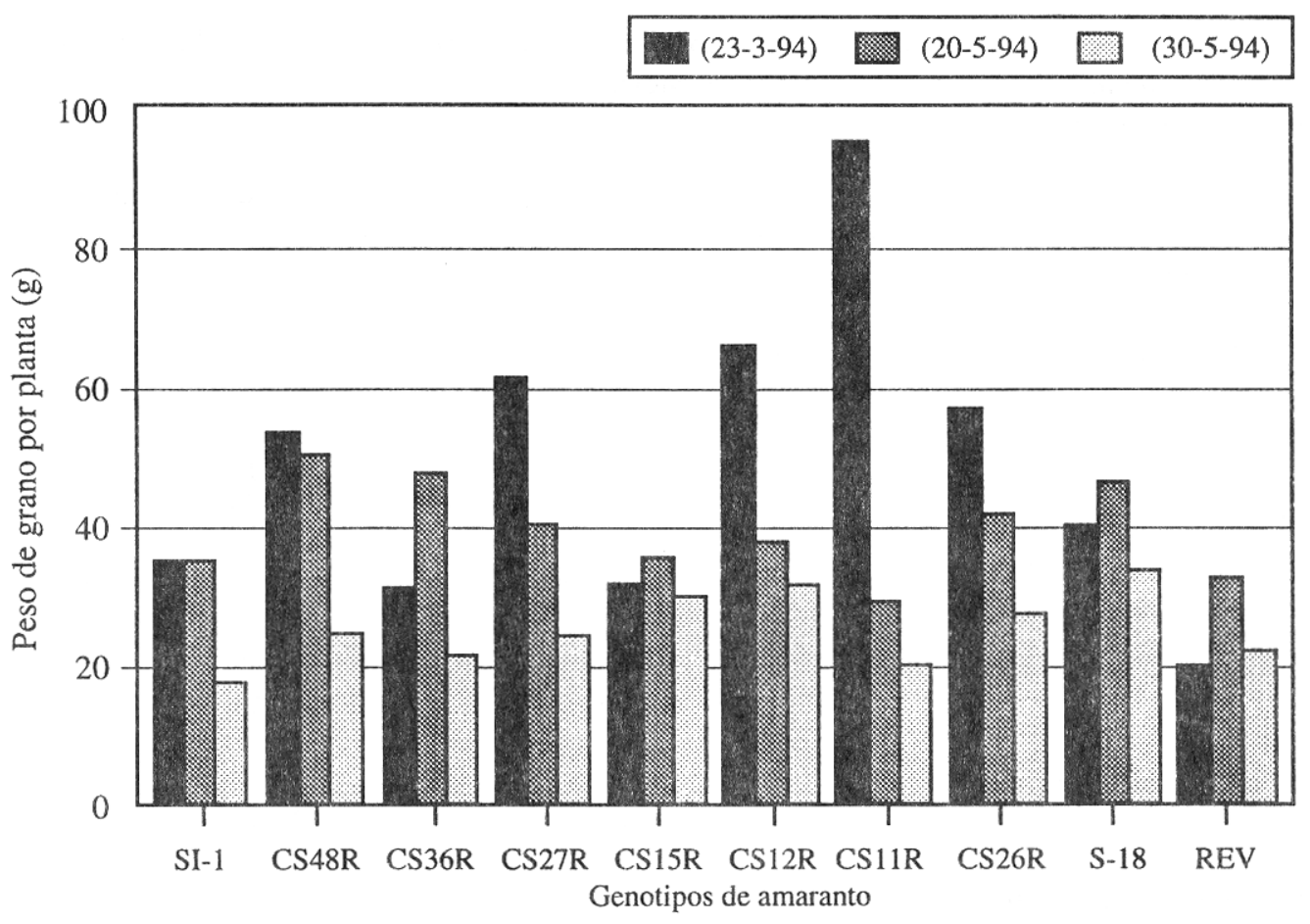

Fig. 2. Rendimiento de diez tipos de amaranto, sembrados en tres fechas de siembra. Chapingo, México.

utilizar fechas de siembra que permitan evadir las épocas de mayor incidencia de lluvia durante el período de crecimiento reproductivo, situación muy difícil de lograr por lo aleatorio de la lluvia en la agricultura de temporal.

También como una observación general, se encontró que el CS se manifestó más en plantas situadas dentro de las parcelas, que en plantas de orilla, por lo que el manejo de densidad de población puede ser una opción para regular la presencia del crecimiento secundario.

En la localidad de Cuapiaxtla, Tlax., en las dos fechas de siembra establecidas, la altura de planta fue más uniforme (1,7 a 2,0 m) y no se presentó crecimiento secundario. La lluvia, desde la emergencia de plantas a la emergencia de la panícula fue de $299,9 \mathrm{~mm}$, y la ocurrida durante el período de crecimiento reproductivo fue tan sólo de 118,2 mm, valor inferior al de la FS2 en Chapingo, en la cual hubo menor manifestación de CS. El ciclo biológico se interrumpió a los 119 días debido a una helada, ocurrida el 29 de septiembre. En este periodo de tiempo se acumularon $418,1 \mathrm{~mm}$ de lluvia, valor inferior al registrado en cualquiera de las tres fechas de siembra establecidas en Ll.

\section{LITERATURA CITADA}

BARRALES D., J.S. 1988. Jardines fenológicos: una herramienta para estudiar la aclimatación de especies cultivadas en zonas de reciente introducción. Revista Chapingo. En prensa.

BARRALES D., J.S.; J. GARCIA R.; M.HERNANDEZ C. 1992. Influencia de la precipitación pluvial sobre el desarrollo de amaranto (Amaranthus hypochondriacus L.). Revista Chapingo. 77:66-70.

BARRALES D., J.S. 1993. Informe técnico del cultivo de amaranto. Fitotecnia. UACH, Chapingo, Mex.

DUNCAN, A.E. 1980. Grain amaranth: Characteristics and culture. New Crops Department. Organic Gardening and Farming Research Center. Report 80-1. Rodale Press mc. USA.

ESPITIA R., E. 1991. Recursos genéticos de amaranto (Amaranthus spp.). In Avance en el estudio de los recursos genéticos de México. pp. 197-216.

GARCIA, E. 1981. Modificaciones al sistema de clasificación climática de Koppen. México. 252p.

GRUBBEN, G. J. H.; H. VAN SLOTEN. 1981. Genetic resources of amaranths. IBPGR-FAO. Rome.Italy. 57p.

REINA T., T. 1990. Requerimientos climáticos para el cultivo del amaranto (Amaranthus spp) en México. In El Amaranto, su cultivo y aprovechamiento. Colegio de Postgraduados Montecillo, Mex. pp. 81-89. 